Research Article

\title{
A Sustainable Economic System to Face the Fluctuation of Fruit Prices: Based on a Small-Region DSGE Model
}

\author{
Hailing Fu $\mathbb{D}^{1},{ }^{1}$ Yuantao Fang $(\mathbb{D})^{2}$ Yi Qu $\mathbb{D}^{3},{ }^{3}$ and Yi Pan $\mathbb{D}^{1}$ \\ ${ }^{1}$ College of Applied Science and Technology, Hainan University, Haikou, Hainan 570228, China \\ ${ }^{2}$ College of Finance, Shanghai Lixin University of Accounting and Finance, 995 Shangchuan Road, Shanghai 201209, China \\ ${ }^{3}$ Newcastle Business School, Northumbria University, Newcastle Upon Tyne, NE1 8ST, UK
}

Correspondence should be addressed to Yuantao Fang; 20190060@lixin.edu.cn

Received 21 December 2020; Revised 19 April 2021; Accepted 3 June 2021; Published 16 June 2021

Academic Editor: Lijun Pei

Copyright (C) 2021 Hailing Fu et al. This is an open access article distributed under the Creative Commons Attribution License, which permits unrestricted use, distribution, and reproduction in any medium, provided the original work is properly cited.

This paper builds a new small-scale and regionalization DSGE model that focuses on the sustainable economic system, which was estimated by the Bayesian estimation method using Chinese annual data from 2004 to 2017 to analyze the effect of the fluctuation of fruit prices in Hainan. We find the fluctuation of increasing prices has a negative effect on fruit output. This results in a preference to loosen monetary policy to reduce this influence and then results in price inflation, which will lead to the increase in output and prices simultaneously. Based on our findings, we provide suggestions for policy maker such as the optimization of industrial structures and increased investment in the fruit industry, extending the fruit industry chain and establishing a multifruit industry sustainable economic system.

\section{Introduction}

Fruit is an important economic crop in China and plays a large role in the national economy. According to FAOSTAT, compared to the rest of the world, China's fruit planting area and output have been consistently number one, and each year, over 675 million metric tons of fruit is produced worldwide. "Early Harvest Program" of the China-ASEAN Free Trade Area (CAFTA) was launched, realizing the market opening of agricultural products. China had eliminated import tariffs on about 600 agricultural products between China and ASEAN's major members, and also the zero-tariff policies have been implemented on tropical fruits in the region. Since the implementation of the plan, bilateral trade in agricultural products has grown rapidly. Meanwhile, on November 15, 2020, the 4th Regional Comprehensive Economic Partnership (RCEP) Leaders' Meeting was held. After the meeting, the 10 ASEAN countries and 15 AsiaPacific countries including China and Japan formally signed "Regional Comprehensive Economic Partnership Agreement." Signing the agreement marks the official start of the free trade zone with the largest population, the largest economic and trade scale, and the most development potential in the world. It promotes the development of China's tropical fruit processing industry, but it also has a great impact on the tropical fruit industry with Chinese characteristics, which complicates the adjustment and optimization of China's tropical fruit industrial structure. As one of the most important consumer goods, the price of fruit is high and fluctuating, which has a devastating effect on developing countries and the world's poor populations [1]. Therefore, it is a serious task to reform traditional agriculture, fine-tune tropical fruit industry structure with Chinese characteristics, increase farmers' income, and promote sustainable and healthy agricultural development.

Hainan is an important area for the development of tropical agriculture in China. It is located at the northern latitude $18^{\circ} 10^{\prime}-20^{\circ} 10^{\prime}$ and eastern longitude $108^{\circ} 37^{\prime}-111^{\circ} 03^{\prime}$ with 33,920 square kilometers $(13,100 \mathrm{sq}$. mi) of tropical area. It has precipitation of $1437.0-3022.7 \mathrm{~mm}, 23.4-26.5^{\circ} \mathrm{C}$ average temperature, and 1573.5-2443.4 hours of annual daylight. This makes it a suitable place for tropical fruit production. The tropical fruit industry is an important part of the Hainan economy system. Table 1 shows the annual 
TABle 1: Annual fruit GDP of Hainan province from 2010 to 2019.

\begin{tabular}{|c|c|c|c|c|c|c|c|c|c|c|}
\hline Year & 2010 & 2011 & 2012 & 2013 & 2014 & 2015 & 2016 & 2017 & 2018 & 2019 \\
\hline Fruit GDP & 12019 & 11088 & 10608 & 12388 & 15002 & 15784 & 18263 & 20232 & 20178 & 25654 \\
\hline$\%$ of GDP & $5.82 \%$ & $4.40 \%$ & $3.71 \%$ & $3.90 \%$ & $4.29 \%$ & $4.26 \%$ & $4.52 \%$ & $4.53 \%$ & $4.18 \%$ & $4.83 \%$ \\
\hline
\end{tabular}

Unit: million RMB, Source: Statistical Yearbook of Hainan Province and National Bureau of Statistics of China.

tropical fruit farming GDP of Hainan province from 2010 to $2019,4 \%$ to $5 \%$ of the entire GDP of Hainan on average. Hainan's tropical fruit production not only supplies other provinces, but also the tropical fruit industry is becoming more and more important to the Hainan economy.

However, due to the nature of fruit and economic factors, fruit prices are inevitably faced with the dual pressures of natural risks and market risks. As Ma and Sun [2] proposed, with the expansion of the price adjustment parameter, the economic system shows a wealth of complex features and enters the chaos period. The long production cycle and the time between the production decisions and market sales, and the lag in time taken for the adjustment of market prices to production, directly lead to fruit price fluctuations. The fluctuation of the fruit price affects the entire fruit industry and the total GDP growth. This results in economic policies reducing the relevant negative influences and ensuring healthy economic growth. The research of Wandong Lou and Junhai Ma [3] shows that the adjustments of price would affect the stability and profits much more than the sales effort in economic system. They proposed that every supply chain should take the suitable adjustment speeds for the price to keep the system in the stable state.

The current research aims at tropical fruits of Hainan to analyze the effect of the fluctuation of fruit price on its economic system. This kind of economic system has the characteristics of small scale and regionalization. Based on the researches of Ireland [4] and Smets and Wouters [5], from the side of supply-side structural reform, we build a small-scale, regionalization, and specialized DSGE model estimated by the maximum likelihood method using annual Chinese data from 2004 to 2017, with the purpose of developing a sustainable economic system of tropical fruit industry in Hainan.

This study contributes three innovations to the scientific literature. Firstly, it adds a fruit variable into consumption and production as raw materials for consumer goods and intermediate products, respectively. Secondly, under the framework of dynamic stochastic general equilibrium (DSGE), this paper divides fruit into fruit consumer goods and fruit production raw materials in the household sector and the manufacturing sector, respectively. At the same time, the fruit price also enters the optimization problem of representative households and companies in the form of random variables. This is to study the dynamic impact of fruit price shocks on Hainan's macroeconomy. We also add fruit price shocks to investigate the impact on various variables in Hainan's economy. Thirdly, the model consists of representative households and representative companies; among them, the family consumes two types of consumer goods: fruit consumer goods and non-fruit consumer goods.
Simultaneously, it also provides labor and private capital to manufacturers for remuneration and capital rent, while manufacturers make use of labor, capital, and fruit-based raw materials for production.

In the next section, we review the relevant literatures. The rest of the paper is as follows. Section 3 discusses the general model of this study. Section 4 presents the data and the analysis of the model results. Finally, Section 5 provides conclusions, policy suggestions, and possible future research directions.

\section{Literature Review}

Economists and central banks frequently use DSGE models to analyze macroeconomies and to evaluate economic policy [6]. During the past decade, DSGE models have been gaining popularity and become the standard framework for monetary policy, economic fluctuation, and economic forecasting. Studies have been made on economies of different levels of development. Kang and Suh [7] researched the influence of the global financial crisis and labor markets on GDP growth through a DSGE model sample of the more advanced economy of South Korea. Pop [8] used a DSGE model to analyze the relation between inflation and monetary policy in Romania, an emerging economy. Bondzie et al. [9] studied the oil price fluctuations and the relevant influence on the economic growth based on a DSGE approach. Smets and Wouters [10] investigated the business cycle of US economy and estimated a DEGE model using Bayesian methods $[11,12]$. Meanwhile, DSGE models have particularly been employed in the research literature on China's economic growth and development. Different types of DSGE models have been developed and applied by researchers in diverse studies. He et al. [13] found that the housing market shocks, such as the housing preference shocks and the loan-to-value ratio, influence the macroeconomy of China based on DSGE analysis. Mehrotra et al. [14] focused on the costs in capital adjustment, habit formation in consumption, and price rigidities, developing a small-scale DSGE model to explore the impact of Chinese economic rebalancing after responding to different shocks. Miao and Peng [15] applied the new Keynesian DSGE model to explore the root of business cycles in China and noted that inflation, productivity, and credit shocks are the three driving forces of the economic fluctuations in China. Jia et al. [16], by developing an open economy model, researched the shocks for the trade-offs on the fiscal and monetary policy aspects.

Due to China's unique institutional structure, different aspects of rule-based DSGE frameworks have gradually become more popular in the study of China's macroeconomic policy. Until now, however, there is no consensus on 
which kind of rule is better in DSGE frameworks to characterize China's macroeconomic policy. Kenichi Tamegawa [6] pointed out that small regions' policy makers need an effective small-region DSGE model to evaluate their policies, or they will be forced to use traditional macroeconomy models. Because the Hainan economic system has the characteristics of small-scale and regionalization, we try to develop a small-region DSGE model to research it.

Fruit price mainly affects the macroeconomy in two ways. First, from the aspect of supply, the rise of fruit prices leads to the rise of purchasing costs of related companies, which in turn leads to a decrease of output and the slowdown of economic growth. At the same time, it also causes the emergence of industrial structure adjustment, and structural unemployment appears, and macroeconomic prosperity declines. Second, from the demand side, the rise of fruit prices raises overall inflation, which in turn leads to a decrease in real income of citizens and a decrease in total consumption. At the same time, rising fruit prices can also cause reduced citizens' demand for fruit-based consumer goods, reduced risk appetite, and increased "cautious saving." Therefore, the price is the main factor affecting supply and demand. The demand-supply evolution is periodic as the provider alternates between cultivating and exploiting the herd effect [17].

The existing notable studies almost solely focus on the entire country's economy. There is limited study on the special tropical agriculture province of China. In this paper, for our research, we concentrate on Hainan Province through the new small-scale, regionalization, and specialized DSGE model estimated by the maximum likelihood method using Chinese yearly data of 2004-2017 to analyze the effect of the fluctuation of fruit price on its economy.

\section{General Model}

Our benchmark model economy, which is a slightly modified version taken from Liu and Song [18], consists of the representative household, finished goods-producing firm, intermediate goods producing firm, and central bank.

As shown in Figure 1, households provide capital to intermediate goods producing companies and receive labor income, which is divided into two parts: one part is investment, and the other part is consumption. Consumption of goods includes two kinds: fruit goods and non-fruit goods. Intermediate goods producing companies will use fruit, capital, and labor to produce intermediate goods while maximizing profit and then sell these intermediate goods to finished goods-producing companies. Note that fruit, as part of final goods, will be used to produce intermediate goods and consumed by households.

3.1. Representative Household. Assume that the representative household enters each time period $t=0,1,2,3, \ldots$ by maximizing the utility function:

$$
E_{0}\left[\sum_{t=0}^{\infty} \beta^{t} U\left(C_{t}^{k}\left(F_{t}^{h}\right)^{1-k}, \frac{M_{t}}{P_{t}}, h_{t}\right)\right]
$$

where $\beta$ is discount factor and $0<\beta<1$, meaning that the representative household pursues the maximization of the lifetime utility present value.

Spot utility function of the representative household:

$$
U\left(C_{t}^{k}\left(F_{t}^{h}\right)^{1-k}, \frac{M_{t}}{P_{t}}, h_{t}\right)=a_{t}\left[\frac{\left(C_{t}^{k}\left(F_{t}^{k}\right)^{1-k}\right)^{1-\sigma_{c}}}{1-\sigma_{c}}+\frac{\left(M_{t} / P_{t}\right)^{1-\sigma_{m}}}{1-\sigma_{c}}\right]-\frac{h_{t}^{1+\sigma_{2}}}{1+\sigma_{2}}
$$

where $C_{t}$ is the nonfruit consumption of goods; $F_{t}^{h}$ is the fruit consumption of goods; $h_{t}$ is the labor supply; $M_{t}$ is the money held at the end of time $t ; \sigma_{c}, \sigma_{m}$ and $\sigma_{L}$ are all greater than 0 , and $1 / \sigma_{c}, 1 / \sigma_{m}$ and $1 / \sigma_{L}$ represent the intertemporal substitution elasticity of consumption, the interest rate elasticity of money demand, and the Frisch elasticity of labor supply.

The preference shock of consumption is as follows:

$$
\ln \left(a_{t}\right)=\left(1-\theta_{a}\right) \ln (a)+\theta_{a} \ln \left(a_{t-1}\right)+\varepsilon_{t}^{a},
$$

where $0 \leq \delta_{a} \leq 1 . \varepsilon_{t}^{a}$ follows a normal distribution with mean 0 and variance $\sigma_{a}^{2}$.

The intertemporal budget constraint faced by the representative household for the periods $t=0,1, Z, \ldots, n$ is

$$
w_{t} h_{t}+B_{t-1}+T_{t}+M_{t-1}+D_{t}+R_{t}^{k} K_{t-1} \geq P_{t} C_{t}+P_{t}^{0} F_{t}+\frac{B_{t}}{r_{t}}+M_{t}
$$

where $B_{t}$ is the total bond at the end of time $t ; w_{t}$ is the nominal wage rate for the time period; $T_{t}$ is the transfer payment; $\mathrm{M}_{t-1}$ is the money holding with a lag of one period; $R_{t}^{k} K_{t-1}$ is the nominal income from capital rental. At the end of the period $t$, the household receives a nominal profit share $D_{t}=\int_{0}^{1} D_{t}(2) \mathrm{d} i(2) d_{i}$ from the intermediate goods producing companies $i \in[0,1]$, where $D_{t}(\mathrm{i})$ is the profit earned from the company $i$ at the time period $t$.

Capital function:

$$
K_{t}=(1-\theta) K_{t-1}+\left[1-S\left(\frac{x_{t} i_{t}}{i_{t-1}}\right)\right] i_{t},
$$

where $\theta$ is the capital depreciation rate, and $s$ is the cost of capital adjustment with $s^{\prime}=0 . X_{t}$ is the capital adjustment cost shock with

$$
\operatorname{Ln}\left(X_{t}\right)=\left(1-\theta_{x}\right) \ln (X)+\theta_{x} \ln \left(X_{t-1}\right)+\varepsilon_{t}^{X},
$$




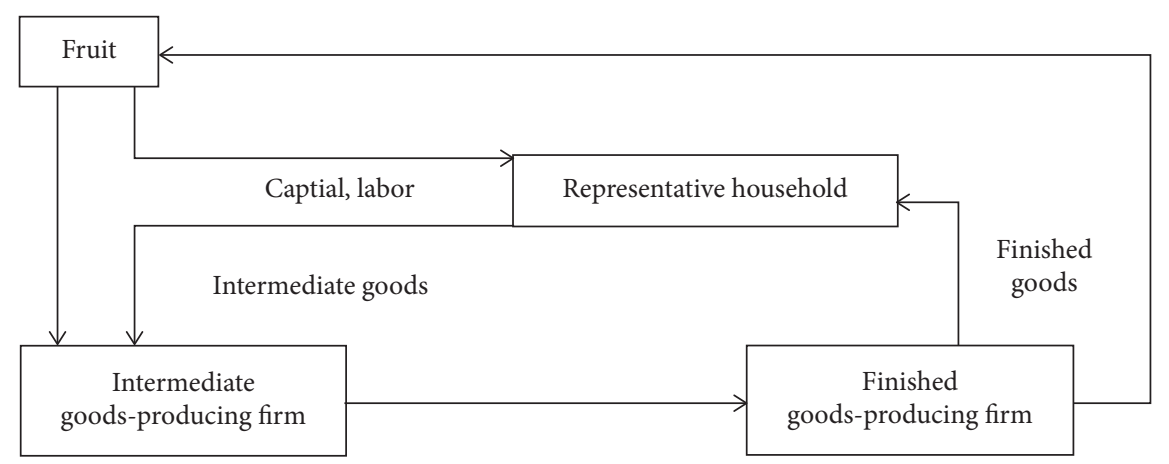

Figure 1: The basic structure of model.

where $0 \leq \theta_{x}<1$ and $\varepsilon_{t}^{x}$ follows normal distribution with mean 0 and variance $\sigma_{x}^{2}$.

We assume in this model that the labor supply is heterogeneous, and the household is the price maker. We use the sticky prices assumption of $\mathrm{Wu}$, and Chang [19]. At the end of time $t$, only $\left(1-\xi_{w}\right)$ households could get the best price, while other households adjust price according to the last period, which is

$$
W_{t}(j)=\pi_{t-1} W_{t-1}(j) .
$$

Assume that the labor supply market has a perfect system, and the market could adjust itself to get the maximum profit, which decides the best amount of each kind of labor j:

$$
\operatorname{Max}\left\{W_{t} h_{t}-\int_{0}^{1} W_{t}(j) h_{t}(j) \mathrm{d} j\right\},
$$

where $W_{t}$ is the nominal wage, and $W_{t}(j)$ is the wage level of household $j$, while $h_{t}(j)$ represents the labor demand of household $j$.

The total labor demand:

$$
h_{t}=\left[\int_{0}^{1} h_{t}(j)^{\left(\theta_{t}^{w}-1\right) / \theta_{t}^{\omega}} \mathrm{d} j\right]^{\theta_{t}^{\omega} /\left(\theta_{t}^{w}-1\right)},
$$

where $\theta_{t}^{w}$ is the wage elasticity of the labor demand.

When the market reaches equilibrium, the profit of total labor supply is zero; thus, we get

$$
\begin{aligned}
W_{t} & =\left[\int_{0}^{1} W(j)^{1-\theta_{t}^{w}} \mathrm{~d} j\right]^{1 /\left(1-\theta_{t}^{w}\right)} \\
& =\left[\xi_{w}\left(\pi_{t-1} W_{t-1}\right)^{1-\theta_{t}^{w}}+\left(1-\varepsilon_{w}\right) \bar{w}_{t}^{1-\theta_{t}^{w}}\right]^{1 /\left(1-\theta_{t}^{w}\right)} .
\end{aligned}
$$

Define $\gamma_{t+k}^{w}=\theta_{t}^{w} / \theta_{t}^{w}-1$, and then wage plus shock is $\gamma_{t+k}^{w}$

$$
\ln \left(\gamma_{t}^{w}\right)=\left(1-\theta_{y^{w}}\right) \ln \gamma+\theta_{y^{w}} \ln \left(\gamma_{t-1}^{w}\right)+\varepsilon_{t}^{\gamma^{w}},
$$

where $0 \leq \theta_{y^{w}}<1$ and $\varepsilon_{t}^{\gamma^{w}}$ follows normal distribution with mean 0 and variance $\sigma_{\gamma^{w}}^{2}$.

3.2. Finished Goods-Producing Company. According to Ireland [4], the finished goods-producing company buys $Y_{t}(i) \mathrm{i} \in[0,1]$ units of the intermediate goods at the price
$P_{t}(i)$ to produce $Y_{t}$ units of the finished goods using the constant-return-to-scale technology described by

$$
\left[\int_{0}^{1} Y_{t}(i)^{\left(\theta_{t}^{p}-1\right) / \theta_{t}^{p}} \mathrm{~d} i\right]^{\theta_{t}^{p} /\left(\theta_{t}^{p}-1\right)},
$$

where $\theta_{t}$ is the elasticity of demand for the intermediate goods, which follows the autoregressive process:

$$
\ln \left(\theta_{t}^{p}\right)=\left(1-\rho_{\theta}\right) \ln (\bar{\theta})+\rho_{\theta} \ln \left(\theta_{t-1}^{p}\right)+\varepsilon_{\theta_{t}},
$$

where $\bar{\theta}>1$ and $1>\theta_{t}^{p} \geq 0$.

As the finished goods-producing firms face perfect competition capital and goods markets, each firm will decide to maximize its profit given $P_{t}(i)$ and $P_{t}$, which leads to the demand of intermediate goods:

$$
Y_{t}(i)=\left[\frac{P_{t}(i)}{P_{t}}\right]^{-\theta_{t}^{p}} Y_{t}
$$

As for intermediate goods, $\theta_{t}^{p}$ is the same. Competition will lead to the zero profit of the finished goods-producing company, which will decide $P_{t}$ as follows:

$$
P_{t}=\int_{0}^{1} P_{t}(i)^{1-\theta_{t}^{p}} d_{i}
$$

3.3. Intermediate Goods-Producing Companies. Assume that all firms have infinite life and distribute continuously $[0,1]$. We consider the intermediate goods-producing firm $i$ who uses labor, capital, and original fruit to produce goods by the Cobb-Douglas function.

$$
Y_{t}(i)=z_{t} h_{t}(i)^{\partial_{1}} k_{t-1}(i)^{\partial_{2}} F_{t}^{f}(i)^{\partial_{3}},
$$

where $\partial_{1}, \partial_{2}$ and $\partial_{3}$ are all greater than 0 and $\partial_{1}+\partial_{2}+\partial_{3}=1$. $Z_{t}$ is the technology shock as follows:

$$
\ln \left(Z_{t}\right)=\left(1-\delta_{z}\right) \ln (Z)+\delta_{z} \ln \left(Z_{t-1}\right)+\varepsilon_{t}^{z},
$$

where $0 \leq \delta_{z}<1$ and $z>0$. $\varepsilon_{t}^{z}$ follows normal distribution with mean 0 and variance $\sigma_{z}^{2}$.

The company faces a perfect competition input demand market. It can hire $h_{t}$ unit labor with fixed price $W_{t}$, rent $k_{t-1}$ unit capital with fixed rent rate $R_{t}^{k}$ and buy $F_{t}^{f}$ original fruit 
with fixed price $P_{t}^{f}$ to produce $\gamma_{t}(i)$ intermediate-producing goods. The cost function is as follows:

$$
C_{t}(i)=R_{t}^{k} K_{t-1}(i)+W_{t} h_{t}(i)+P_{t}^{f} F_{t}^{f} .
$$

Assume that the fruit price is as follows:

$$
\ln \left(P_{t}^{f}\right)=\left(1-\delta_{p f}\right) \ln \left(P^{f}\right)+\delta_{p f} \ln \left(P_{t-1}^{f}\right)+\varepsilon_{t}^{p f},
$$

where $1 \geq \delta_{p f} \geq 0, P^{f}>0$ and $\varepsilon_{t}^{p f} \sim \mathrm{N}\left(0, \delta_{p f}^{2}\right)$.

The marginal cost $C_{t}(i) / y_{t}(i)=1 / Z_{t} \partial_{1}^{-\partial 1} \partial_{2}^{-\partial 2} \partial_{3}^{-\partial 3}$ $\left(W_{t}\right)^{\partial 1}\left(r_{1}^{k}\right)^{\partial 2}\left(p_{t}^{f}\right)^{\partial 3}$, is related to the technology level and input price, which is suitable for all intermediate goodsproducing companies.

We use the sticky prices assumption of Calvo [20]. As adjusting price will affect the preference of consumers and increase the management cost, firms can only adjust it cyclically. Assume that, for each period, only $\left(1-\xi_{p}\right)$ intermediate goods-producing companies could get the best price to sell goods and other companies adjust price according to the last period as follows:

$$
\begin{gathered}
P_{t}(i)=E_{t}\left(\pi_{t}\right) P_{t-1}(i), \\
E_{t}\left(\pi_{t}\right)=\left(\pi_{t}^{\operatorname{targ}}\right)^{z}\left(\pi_{t-1}\right)^{1-z},
\end{gathered}
$$

where $\pi_{t-1}=P_{t-1} / P_{t-2}$ represents the measurable inflation of the last period.

$\pi_{t}^{\text {targ }}$ is the target inflation of the central bank, which is assumed to be equal to the stable value of inflation. follows:

Define $\gamma_{t+k}^{p}=\theta_{t}^{p} / \theta_{t}^{p}-1$, and then price plus shock is as

$$
\ln \left(\gamma_{t}^{p}\right)=\left(1-\theta_{\gamma p}\right) \ln \gamma+\theta_{\gamma p} \ln \left(\gamma_{t-1}^{p}\right)+\varepsilon_{t}^{\gamma^{p}},
$$

where $0 \leq \theta_{\gamma p}<1$, and $\varepsilon_{t}^{\gamma^{p}}$ is a normal distribution with mean 0 and variance $\sigma_{\gamma^{p}}^{2}$.

The total price is as follows:

$$
\begin{aligned}
P_{t} & =\left[\int_{0}^{1} P(i)^{1-\theta_{t}^{\sigma}} \mathrm{d} i\right]^{1 /\left(1-\theta_{t}^{\sigma}\right)} \\
& =\left[\xi_{p}\left(\pi_{t-1} p_{t-1}\right)^{1-\theta_{t}^{\sigma}}+\left(1-\xi_{p}\right) \bar{p}_{t}^{1-\theta_{t}^{\sigma}}\right]^{1 /\left(1-\theta_{t}^{\sigma}\right) .}
\end{aligned}
$$

Meanwhile, final goods will be divided into two parts: fruit goods include those used to produce intermediate goods and those consumed by households; non-fruit goods will be consumed and invested by households. Thus, the final goods should be satisfied:

$$
Y_{t}=C_{t}+i_{t}+P_{t}^{f} F_{t}^{f}+P_{t}^{f} F_{t}^{h}
$$

3.4. Central Bank. The monetary policy model of the central bank refers to Ireland [4], assuming that the central bank corrects the gap between output $y_{t}$ and inflation $\pi_{t}$ by adjusting the linear combination of short-term nominal interest rate $r_{t}$ and monetary growth rate $_{t}$, and the monetary growth rate satisfies

$$
\mu_{t}=\frac{M t}{M t-1} \text {. }
$$

Inflation rate is defined by

$$
\pi_{t}=\frac{P_{t}}{P_{t-1}}
$$

According to the rule of monetary policy,

$$
\ln \left(\frac{r_{t}}{r}\right)=\omega_{r} \ln \left(\frac{r_{t-1}}{r}\right)+\left(1-\omega_{r}\right)\left[\omega_{\pi} \ln \left(\frac{\pi_{t}}{\pi}\right)+\omega_{y} \ln \left(\frac{y_{t}}{y}\right)+\omega_{\mu} \ln \left(\frac{\mu_{t}}{r}\right)\right]+\ln \left(V_{t}\right)
$$

where $\omega_{r}, \omega_{\mu}, \omega_{y}$ and $\omega_{\pi}$ are decided by the central bank; $r, \mu$, $y$ and $\pi$ are the stead values of $r_{t}, \mu_{t}, y_{t}$ and $\pi_{t}$. When $\omega_{\mu}=0$, it becomes the Taylor [21] rule; when $\ln \left(r_{t} / r\right)=\ln \left(r_{t-1} / r\right)=$ 0 and $\omega_{\pi}=0$, it is consistent with the policy rule, as the central brand adapts to an increase in the output only by increasing the money supply [22]. Finally, when $\ln \left(r_{t} / r\right)=$ $\ln \left(r_{t-1} / r\right)=0$ and $\omega_{y}=\omega_{\pi}=0$, it is consistent with Rotemberg [23]. The shock of monetary policy $v_{t}$ is as follows:

$$
\ln \left(V_{t}\right)=\left(1-\rho_{v}\right) \ln (V)+\rho_{v} \ln \left(V_{t-1}\right)+\varepsilon_{t}^{v},
$$

where. $0 \leq \rho_{v}<1$ and $\varepsilon_{t}^{v} \sim N\left(0, \sigma_{v}^{2}\right)$

\section{Model Results}

4.1. Data. The data used in this paper is the total output, investment, money supply, wages, inflation, and the percentage change of fruit consumption from state values. The data is from 2004 to 2017. We use GDP and The Total Sales of
Consumer Goods as total output in Hainan, Total Investment in Fixed Assets as investment, M2 in Hainan as money supply, and the Total Output of Fruit Production as fruit consumption. The inflation is calculated using CPI in 2004 as the base element.

4.2. Parameter Estimation. The parameters in this paper are calculated using two methods. For some fixed parameters, the values are taken from the literature related the Chinese economy. For dynamic parameters, we estimate them using a Bayesian method.

The total number of parameters in this paper is 11: $\beta, \sigma_{L}$, $\zeta, \delta, \partial_{1}, \partial_{2}, \partial_{3}, \sigma_{M}, \varepsilon_{c}, \varepsilon_{i}, \varepsilon_{f}$.

$\beta$ is the discount factor. In China, the interest rate for a one-year deposit is $2.75 \%$; therefore, we get the value of $\beta$ as 0.973. $\sigma_{L}$ is the rate of labor negative utility. When we assume that the labor supply market is a monopoly competitive market, the value of $\sigma_{L}$ is between 0.3 and 1 [18]. 
Based on the study by CMR (2007), we set the value of $\sigma_{L}$ to be equal to $1 . \sigma_{M}$ is the rate of monetary utility, based on Tong [24], and we choose 1.4 as the value of $\sigma_{M}$.

$\delta$ is the capital depreciation rate, which is equal to $10 \%$ for one year in this paper as the previous research [19]. $\zeta$ represents the monopoly level of the market. $\zeta$ can be calculated by the steady-state price addition of $\theta^{\omega}$. Based on Ireland [4], we choose 6 as the value of $\theta^{\omega}$, and then the value of $\zeta$ is 1.2 , which means that the steady state price plus is $20 \%$.

$\partial_{1}, \partial_{2}$ and $\partial_{3}$ represent the ratio of input during the process of intermediate goods production. Based on Tong [24] calculated the actual data of China by the income approach and developed the value of $\partial_{1}$ to be 0.6 , which means that the labor income accounts for $60 \%$ of the total income of intermediate products in the steady state. According to Ireland [4], the assumed value of $\partial_{2}$ is 0.21 . Because $\partial_{1}+\partial_{2}+\partial_{3}=1$, the calculated value of $\partial_{3}$ is 0.19 .

According to the calculation, $\varepsilon_{c}$, $\varepsilon_{i}$ and $\varepsilon_{f}$ represent the ratio of non-fruit consumption, investment, and fruit consumption to GDP, which are $0.372,0.528$, and 0.1 , respectively. Table 2 shows the definitions and the values of fixed parameter.

The number of dynamic parameters in this paper is $24 . \sigma_{c}$ and $k$ are the economic behaviors of representative household, $\psi$ is the investment behaviours, $\xi_{w}$ is the wage pricing process, $\xi_{p}$ and $\tau$ are the product pricing process, and $\omega_{r}, \omega_{\pi}, \omega_{y}$ and $\omega_{\mu}$ are the process of monetary policy. Then, 7 shocks are defined with 14 parameters. The initial distributions are given in Table 3.

According to the Bayesian estimates, the intertemporal consumption elasticity of substitution $1 / \sigma_{-} c$ is 0.728 , which means that the interest rate has a large effect on the household consumption level. When the interest rate rises, people will save more and consume less. Non-fruit consumption rate $k$ is 0.743 , and fruit consumption rate $1-k$ is 0.257 , which means that, in Hainan, fruit consumption takes up a large proportion of total consumption. The value of investment adjustment cost $\psi$ is 4 , which means that, in China, it takes a long time for an investment plan to operate.

The value of price adjustment probability $\xi_{p}$ is 0.79 , which means that, in China, the goods price is extremely sticky. This means that, every year, $21 \%$ of companies can adjust their price, while $79 \%$ of companies cannot adjust their price and remain profitable. The value of wage adjustment probability $\xi_{w}$ is 0.81 , which means that, in China, $19 \%$ of people can adjust their wage. The value of $\tau$ is 0.47 .

For the central bank reaction coefficient, the value of $\omega_{y}$ is 2.83 , and the value of $\omega_{\pi}$ is 1.07 , which means that, in China, monetary policy is correlated with output. The value of $\omega_{r}$ is 0.25 , and the value of $\omega_{\mu}$ is 2.77 , which means that the impact of interest rates is smaller than the impact of money supply. This is consistent with the observed Chinese situation, where money supply plays a large role in the economy.

For the shock descriptive parameters, $\theta_{x}, \theta_{t}^{w}, \delta_{z}, \delta_{p f}$ and $\rho_{v}, \theta_{a}, \gamma_{t}^{p}$ are all greater than 0.5 , which means that, for consumption preference shock, price shock, fruit price shock, and monetary policy shock, they are all coherent. For the shock relative fluctuation, $\sigma_{a}^{2}, \sigma_{x}^{2}, \delta_{p f}^{2}$ and $\sigma_{v}^{2}, \sigma_{\gamma^{w}}^{2}, \sigma_{\gamma^{p}}^{2}$,
TABLE 2: Fixed parameter definitions and their values.

\begin{tabular}{lcc}
\hline Parameter & Definition & Value \\
\hline$\beta$ & Discount factor & 0.973 \\
$\sigma_{L}$ & The rate of labor negative utility & 1 \\
$\zeta$ & Monopoly level of market & 1.2 \\
$\delta$ & Capital depreciation rate & 0.01 \\
$\partial_{1}$ & Labor elasticity & 0.6 \\
$\partial_{2}$ & Capital elasticity & 0.21 \\
$\partial_{3}$ & Fruit elasticity & 0.19 \\
$\sigma_{M}$ & The rate of monetary utility & 1.4 \\
$\varepsilon_{c}$ & Nonfruit consumption to GDP & 0.372 \\
$\varepsilon_{i}$ & Investment to GDP & 0.528 \\
$\varepsilon_{f}$ & Fruit consumption to GDP & 0.1 \\
\hline
\end{tabular}

and $\sigma_{z}^{2}$ are all greater than 0.1 , which means that the violation of these four variables is greater.

4.3. Impulse Analysis. According to the calibration and the parameter values of Bayesian estimation, which are mentioned above, the impulse response diagram of a single fruit price shock to 11 macroeconomic variables such as output, consumption, investment, inflation, labor demand, real money balances, nominal interest rates, value of capital investment, real wages, fruit products consumption, and fruit raw materials input were simulated to analyze the different effects of fruit price shock on macroeconomic fluctuations. It is worth noting that the impulse response diagram of this model is not the actual values of these 11 variables, but the deviations from steady-state values.

As shown in Figure 2, the rapid increase in the price of fruit would have a significant negative impact on Hainan's economy. When the price of fruit rises by $1 \%$, the total output of Hainan Province will fall by $0.04 \%$, as shown in Figure 2(a). The rising prices of the fruit will lead to higher production costs and reduced output in the related industry. However, the fruit industry is the pillar industry of Hainan province, and with the fruit price rising, the output of fruit industry will be reduced correspondingly, and then the GDP of Hainan will be influenced. At the same time, the fruit price shock also impacts the inflation of Hainan province. When the price of fruit rises by $1 \%$, the CPI will fall by $0.2 \%$, as shown in Figure 2(b). The production costs will be increased with the rising prices of fruit, and it will result in the costpush inflation.

The results shown in Figure 3 are consistent with the Chinese economy: there is higher GDP growth and higher inflation at the same time. Accordingly, the money supply increases by $0.09 \%$ and then decreases, which is consistent with Chinese monetary policy, as shown in Figure 3(a). The investment will go up by 0.03 due to the rapid increase in the price of fruit, as shown in Figure 3(b). This is easy to understand, as higher price will attract people to do the investment. The consumption of fruit decreases by $0.05 \%$ when the price of fruit is increasing, as shown in Figure 3(c). This is consistent with the fact that when the price of a good increases, the demand will decrease. Also, when the price of fruit is increasing, the consumption of non-fruit increases by $0.015 \%$, as shown in Figure 3(d). This is also consistent with 
TABle 3: The definitions and initial distributions of the dynamic parameters.

\begin{tabular}{|c|c|c|c|c|c|}
\hline \multicolumn{2}{|r|}{ Dynamic parameters } & \multicolumn{4}{|c|}{ Initial distributions } \\
\hline Parameter & Definition & Distribution & $\begin{array}{l}\text { Prior } \\
\text { mean }\end{array}$ & $\begin{array}{l}\text { Standard } \\
\text { variance }\end{array}$ & $\begin{array}{c}\text { Posterior } \\
\text { mean }\end{array}$ \\
\hline$\sigma_{c}$ & $\begin{array}{c}\text { Reciprocal of intertemporal consumption elasticity of } \\
\text { substitution }\end{array}$ & Normal & 1 & 0.263 & 1.374 \\
\hline$k$ & Nonfruit consumption rate & Normal & 0.8 & 0.1 & 0.743 \\
\hline$\psi$ & Investment adjustment coefficient & Normal & 3.5 & 1 & 4.0 \\
\hline$\xi_{p}$ & Price adjustment probability & Beta & 0.5 & 0.1 & 0.79 \\
\hline$\xi_{w}$ & Wage adjustment probability & Beta & 0.5 & 0.1 & 0.81 \\
\hline$\tau$ & Steady-state inflation weight & Beta & 0.5 & 0.1 & 0.47 \\
\hline$\omega_{r}$ & & Beta & 0.5 & 0.1 & 0.25 \\
\hline$\omega_{\pi}$ & & Gamma & 2.5 & 1 & 1.07 \\
\hline$\omega_{y}$ & Central bank reaction coefficient & Gamma & 2.5 & 1 & 2.83 \\
\hline$\omega_{\mu}$ & & Gamma & 1.5 & 0.5 & 2.77 \\
\hline$\theta_{a}^{n}$ & Consumption preference shock & Beta & 0.5 & 0.1 & 0.703 \\
\hline$\theta_{x}^{u}$ & Investment adjustment shock & Beta & 0.5 & 0.1 & 0.552 \\
\hline$\theta_{t}^{x}$ & Wage plus shock & Beta & 0.5 & 0.1 & 0.676 \\
\hline$\gamma_{t}^{p}$ & Price plus shock & Beta & 0.5 & 0.1 & 0.600 \\
\hline$\delta_{z}$ & Technology shock & Beta & 0.5 & 0.1 & 0.582 \\
\hline$\delta_{p f}$ & Fruit price shock & Beta & 0.5 & 0.1 & 0.537 \\
\hline$\rho_{v}$ & Monetary policy shock & Beta & 0.5 & 0.1 & 0.662 \\
\hline$\sigma_{a}^{2}$ & Consumption preference shock & Inv.gamma & 0.1 & 10 & 0.127 \\
\hline$\sigma_{x}^{a}$ & Investment adjustment shock & Inv.gamma & 0.1 & 0.002 & 0.179 \\
\hline$\sigma_{\gamma^{w}}^{x}$ & Wage plus shock & Inv.gamma & 0.1 & 0.002 & 0.194 \\
\hline$\sigma_{\gamma^{p}}^{2}$ & Price plus shock & Inv.gamma & 0.1 & 0.002 & 0.180 \\
\hline$\sigma_{z}^{2 p}$ & Technology shock & Inv.gamma & 0.1 & 0.002 & 0.203 \\
\hline$\delta_{p f}^{z}$ & Fruit price shock & Inv.gamma & 0.1 & 0.002 & 0.382 \\
\hline$\sigma_{v}^{2 J}$ & Monetary policy shock & Inv.gamma & 0.1 & 0.002 & 0.443 \\
\hline
\end{tabular}

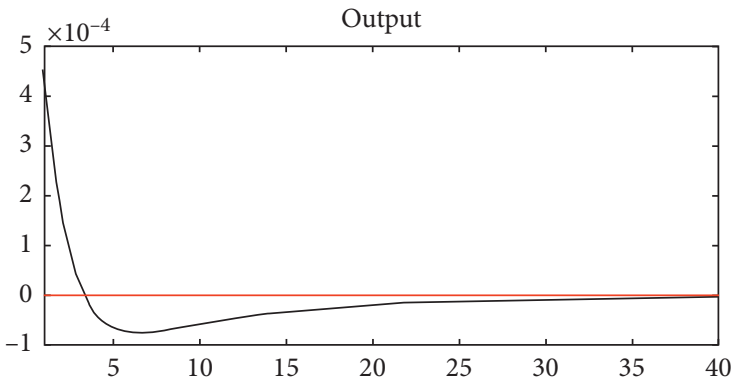

(a)

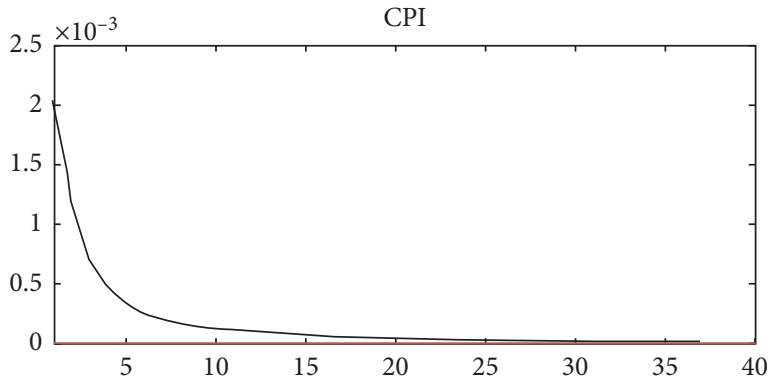

(b)

Figure 2: The effect of fruit price increases on output and CPI.

economics principle. When one good's price is increasing, people will choose to consume other goods, which have lower price. The fruit production input decreases by $0.01 \%$, as shown in Figure 3(e). This is due to the fact that higher price means higher cost. Thus, rational people will choose to input less. Finally, the labor will increase, as shown in Figure 3(f), and wages will increase due to inflation and then decrease, as shown in Figure $3(\mathrm{~g})$.

4.4. Variance Decomposition. We also perform the variance decomposition, which shows the results in Table 4 .
In the short time, the impulse of output comes from itself, which is $42.762 \%$. As time passes, the impulse of output is $14.524 \%$. Meanwhile, the investment has the highest influence on output, which increases from $26.351 \%$ to $36.291 \%$. This implies that investment has the most important influence on economic development, which is consistent with the observed situation in Hainan. The monetary influence is the second most important, which accounts for $23.214 \%$ over the longest time period. This implies that monetary policy has a large effect on the economy. Consumption and CPI have a small effect on output, which implies that these two variables have a lag 


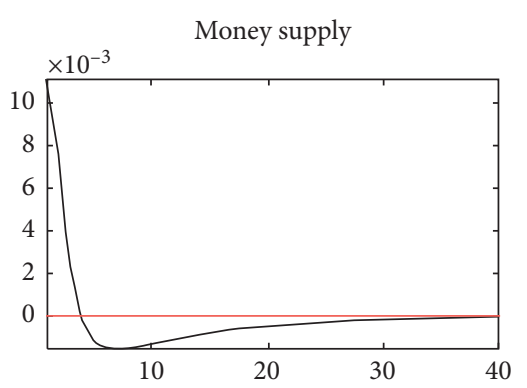

(a)

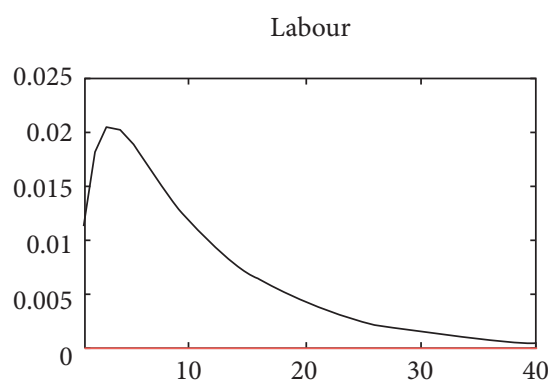

(d)

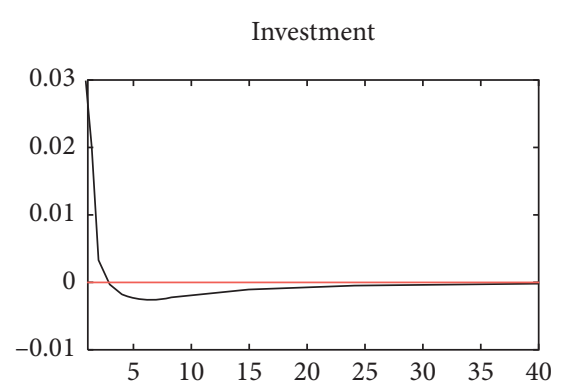

(b)

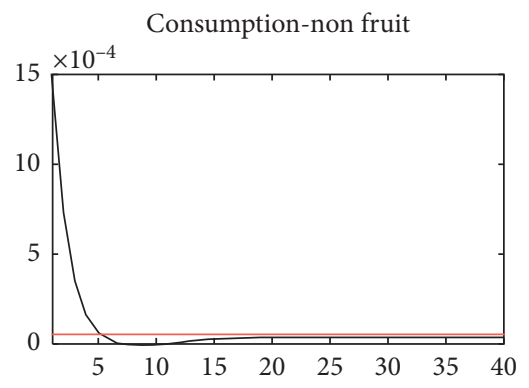

(e)

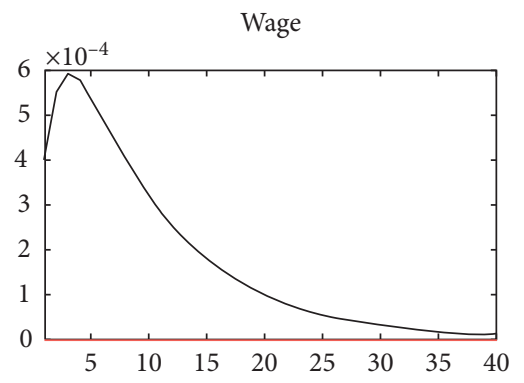

(g)

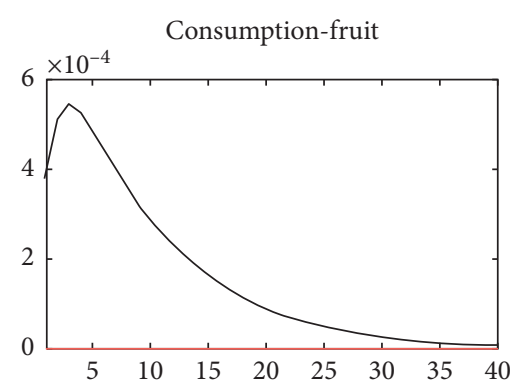

(c)

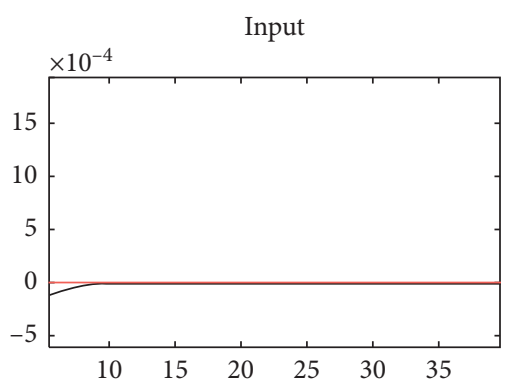

(f)

FIgURE 3: The impulse reaction of variables related to the price of fruit.

TABLE 4: The variance decomposition of variables.

\begin{tabular}{lccccccc}
\hline Time & $Y$ & Con. & Invest. & Money & CPI & Wage & $\begin{array}{c}\text { Fruit } \\
\text { output }\end{array}$ \\
\hline 1 & 100 & 0 & 0 & 0 & 0 & 0 & 0 \\
5 & 42.762 & 0.273 & 26.351 & 17.456 & 0.486 & 11.864 & 0.808 \\
10 & 30.467 & 7.483 & 40.535 & 13.696 & 1.658 & 5.573 & 0.588 \\
15 & 24.568 & 9.474 & 30.357 & 24.956 & 4.283 & 5.728 & 0.634 \\
20 & 20.546 & 8.461 & 34.972 & 23.597 & 7.413 & 4.388 & 0.623 \\
25 & 17.532 & 8.034 & 37.723 & 24.974 & 6.023 & 4.980 & 0.734 \\
30 & 16.753 & 7.975 & 36.671 & 23.592 & 8.542 & 5.872 & 0.595 \\
35 & 15.576 & 8.597 & 37.838 & 22.957 & 8.782 & 5.473 & 0.777 \\
40 & 14.524 & 9.794 & 36.291 & 23.214 & 9.262 & 5.641 & 0.874 \\
\hline
\end{tabular}

effect on output. The effect of wages decreases over time, and the effect of fruit output changes an extremely small amount.

\section{Conclusions and Further Research}

Based on the perspective of sustainable development, this study explores the effective way to solve the competition of tropical fruits industry between China and Southeast Asia.
Based on the demand side of the structure of the adjustment and the macroeconomics perspective, we build a small-scale, regionalization, and specialized DESG model using Chinese annual data from 2004 to 2017 estimated by the maximum likelihood method to analyze the fluctuation of fruit prices on the economy. We find that increasing price has a negative effect on fruit output. When this happens, it is preferable to loosen monetary policy to reduce this influence. The reason is that loosening monetary policy will result in price inflation, which will lead to a decreasing output simultaneously.

In reality, it is difficult to find a case where monetary policy is changed due to price fluctuations of a certain product. Because the monetary and finance systems are extremely complicated nonlinear systems and contain many complex factors [25], we should try to maintain the relative stability of the monetary and finance system. For the quick and healthy development of the economy, it is not too active to be chaotic, which is difficult to forecast and control, nor too faded to lose the energy [25]. From policymaker perspective, government intervention policies can maximize the social welfare [26], but chaos occurs with the increase in the farmer's sensitivity. If government regulates within a reasonable range, the chaos can be controlled, and the system's 
profits rise [27]. Therefore, we put forward some suggestions to promote the sustainable development of fruit industry in Hainan.

Firstly, based on the impact of the fruit price on economy, supply-side structural adjustment should be adopted. We recommend adjusting the supply structure of the fruit industry by developing a sharing economy business system [28] as shared-farms model and gradually integrating the primary, secondary, and tertiary industries, and it will contribute to the sustainable economic system.

Secondly, the rising costs of labor led to the gradual loss of price advantage, and the contribution of competitiveness to the growth of Hainan's fruit exports has rapidly declined [29]. The government should focus on the selection of fruit varieties, optimization of the industrial structure, and supporting policies. The structure of the fruit industry should be adjusted, and a competitive market should be developed with high quality fruit varieties as organic fresh fruits [30]. Planning should be done based on the characteristics of different locations to efficiently build a large base of fruit varieties, while strengthening management and increasing investment or subsidy in science and technology. But attention should be paid to the strategy of subsidies, because subsidy may always have negative impact on the system's stability, which may drive the system operation to be uncontrollable [31].

Thirdly, the investment in the fruit industry should be increased. Banks should provide loans for firms to invest according to the characteristic of economy [32]. It can be seen from our analysis that the investment has a significant stimulating effect on fruit output. Also, the fruit industry chain should be extended by increasing the construction of fruit industry facilities or developing the e-commerce, which will help decrease the natural, technological, and market risks. If the retailer, holding symmetric channel power with the farmer, will increase its profit, in an asymmetric channel power supply chain, the whole profit of supply chain will be lower than the one in a symmetric channel power supply chain [33]. So, developing e-commerce is one of the best ways to hold symmetric channel power and increase its profit.

Fourthly, a multi-fruit industry sustainable system should be established. The prevalence of opportunistic behaviors in agrifood production and circulation results in frequent quality accidents in emerging economies. The quality information tracing technology, farmers, and marketers' fair distribution of profits and risks, and consumers' capabilities to safeguard their legal rights are the three key factors to maintain the effectiveness and stability of quality assurance systems [34]. We should establish a multi-fruit industry sustainable system from the above three aspects. These include the establishment and improvement of early warning systems for damage to the fruit industry and rapid response mechanisms.

There are some different contributions of this study. From the theoretical perspective, we advance the dynamic stochastic general equilibrium model with a new specialized DSGE model, which consists of the representative household, finished goods-producing company, intermediate goods producing company, and central bank. This has not been previously investigated in the macroeconomic literature. In addition, we develop a typology including six different shocks, as well as actual fruit price fluctuation, thus highlighting the importance of studying a sustainable economic system, which includes the fruit industry. On the other hand, from a managerial perspective, through our study, we reveal the link between the fluctuation of increasing fruit prices and fruit output. Also, we make suggestions focusing on the fruit industry sustainable growth for the Hainan economy on some policy aspects.

Though the paper, we explain the phenomena extremely well, and there is scope for further research. This paper uses sticky prices of Calvo [20] to build a small-region DSGE model to explain the effect of fruit prices in Hainan. For the complete DSGE model, we did not consider the effect of monetary policy. Correct monetary policy can effectively help the economy withstand external impacts. The question of whether monetary policy is the main cause of an economic recession after a fruit shock can serve as the focus of future research. By modifying the rules function and adjusting the choice of monetary policy, combined with a small-region DSGE model constructed in this paper, we could, respectively, discuss the performance of the entire economy under the circumstances, where monetary authorities must deal with the inflation gap, the output gap, and no gap. It would serve as a basis to find suitable monetary policy for Hainan to deal with the impact of fruit prices.

\section{Appendix}

\section{Log Linearization Appendix}

$$
\begin{aligned}
\sigma_{m} \widehat{m}_{t}= & \left(\sigma_{c}-\sigma_{c} k\right) \widehat{F}_{t}^{h}=\left(\sigma_{c} k-k+1\right) \widehat{c}_{t}-\frac{\beta}{1-\beta} \widehat{r}_{t}+\frac{\beta}{1-\beta} \widehat{\pi}_{t+1}, \\
\widehat{p}_{t}^{f}= & (1-k) \widehat{c}_{t}-k \widehat{F}_{t-1}^{h}, \\
\widehat{r}_{t}= & \widehat{\pi}_{t+1}-\partial_{t}-\partial_{t+1}+\left(\sigma_{c} k-\sigma_{c}\right)\left(\widehat{F}_{t}^{h}-\widehat{F}_{t-1}^{h}\right) \\
& +\left(k-\sigma_{c} k-1\right)-\left(\widehat{c}_{t}-\widehat{c}_{t-}\right), \\
\widehat{q}_{t}= & \beta(1-\delta) \widehat{q}_{t-1}-r_{t}+\widehat{\pi}_{t+1}+(1-\beta(1-\delta)) \widehat{r}_{t+1}^{k}, \\
\widehat{i}_{t}= & \frac{\beta}{1+\beta} \widehat{i}_{t+1}+\frac{1}{1+\beta} \widehat{i}_{t}+\frac{\psi}{1+\beta} \widehat{q}_{t}+\frac{1}{1+\beta}\left(\beta \widehat{x}_{t+1}-\widehat{x}_{t}\right),
\end{aligned}
$$

where $\psi=1 / s^{\prime \prime}(\cdot)$

$$
\begin{aligned}
& \widehat{k}_{t}=(1-\delta) \widehat{k}_{t-1}+\delta \widehat{i}_{t}, \\
& \widehat{\omega}_{t}=\widehat{k}_{t-1}+\widehat{r}_{t}^{k}-\widehat{h}_{t}, \\
& \widehat{r}_{t}^{k}=\widehat{F}_{t}^{f}+P_{t}^{f}-\widehat{k}_{t-1},
\end{aligned}
$$




$$
\begin{aligned}
& \widehat{\omega}_{t}=\frac{1}{1+\beta}\left(\widehat{\pi}_{t-1}+\widehat{\omega}_{t-1}\right)-\widehat{\pi}_{t} \\
& +\frac{\beta}{1+\beta}\left(\widehat{\pi}_{t+1}+\widehat{\omega}_{t+1}+\frac{\left(1-\beta \xi_{\omega}\right)\left(1-\xi_{\omega}\right)}{(1+\beta) \xi_{\omega}}\right)-\widehat{\omega}_{t}+\sigma_{L} \widehat{h}_{t} \\
& +\left(\sigma_{c}-\sigma_{c} k\right) \widehat{F}_{t}^{h}+\left(\sigma_{c} k-k+1\right) \widehat{c}_{t}+\widehat{\gamma}_{t}^{\omega}, \\
& \widehat{y}_{t}=\widehat{z}_{t}+\partial_{1} \widehat{h}_{t}+\partial_{2} \widehat{k}_{t-1}+\partial_{3} \widehat{F}_{t}^{f}, \\
& \widehat{\pi}_{t}=(1-\tau) \widehat{\pi}_{t-1}+\beta\left(\widehat{\pi}_{t+1}-(1-\tau) \widehat{\pi}_{t}\right) \\
& +\frac{\left(1-\beta \xi_{p}\right)\left(1-\xi_{p}\right)}{\xi_{p}}-\widehat{z}_{t}+\partial_{1} \widehat{\omega}_{t}+\partial_{2} \widehat{r}_{t}^{k}+\partial_{3} \widehat{p}_{t}^{f}+\widehat{\gamma}_{t}^{p}, \\
& \widehat{\mu}_{t}=\widehat{m}_{t}-\widehat{m}_{t-1}+\widehat{\pi}_{t} \\
& \widehat{r}_{t}=\omega_{r} r_{t-1}+\left(1-\omega_{r}\right)\left(\omega_{\pi} \widehat{\pi}_{t}+\omega_{y} \hat{y}_{t}+\omega_{\mu} \widehat{\mu}_{t}\right)+\widehat{v}_{t}, \\
& \widehat{y}_{t}=\frac{C}{Y} \widehat{c}_{t}+\frac{I}{Y} \widehat{i}_{t}+\frac{p^{f} F}{Y}\left(\widehat{F}_{t}^{h}+\widehat{F}_{t}^{f}+\widehat{p}_{t}^{f}\right) .
\end{aligned}
$$

\section{Data Availability}

We build a small-scale, regionalization, and specialized DSGE model estimated by the maximum likelihood method using annual Chinese data from 2004 to 2017, with the purpose of developing a sustainable economic system of tropical fruit industry in Hainan.

\section{Disclosure}

The funders had no role in the design of the study; in the collection, analyses, or interpretation of data; in the writing of the manuscript; or in the decision to publish the results.

\section{Conflicts of Interest}

The authors declare no conflicts of interest.

\section{Acknowledgments}

This research was supported by the project funded by Humanities and Social Sciences Research Innovation Team of Hainan University, Hainan Free Trade Port Cross-Border E-Commerce Service Innovation Research Team (HDSKTD202025). This research was also funded by Hainan Provincial Natural Science Foundation of China (NSFC), under project number 717078, and the Education Department of Hainan Province, under project number hnky2021-2.

\section{References}

[1] A. Rezitis and M. Sassi, "Commodity food prices: review and empirics," Discrete Dynamics in Nature and Society, vol. 2013, Article ID 694507, 15 pages, 2013.
[2] J. Ma and L. Sun, "Complexity analysis about nonlinear mixed oligopolies game based on production cooperation," IEEE Transactions on Control Systems Technology, vol. 26, no. 4, pp. 1532-1539, 2018.

[3] W. Lou and J. Ma, "Complexity of sales effort and carbon emission reduction effort in a two-parallel household appliance supply chain model," Applied Mathematical Modelling, vol. 64, pp. 398-425, 2018.

[4] P. N. Ireland, "Changes in the federal reserve's inflation target: causes and consequences," Journal of Money, Credit and Banking, vol. 39, no. 8, pp. 1851-1882, 2007.

[5] F. Smets and R. Wouters, "An estimated dynamic stochastic general equilibrium model of the euro area," Journal of the European Economic Association, vol. 1, no. 5, pp. 1123-1175, 2003.

[6] K. Tamegawa, "Contructing a small-region DSGE model," Discrete Dynamics in Nature and Society, vol. 2013, Article ID 825862, 9 pages, 2013.

[7] H. Kang and H. Suh, "Macroeconomic dynamics in korea during and after the global financial crisis: a bayesian DSGE approach," International Review of Economics \& Finance, vol. 49, pp. 386-421, 2017.

[8] R.-E. Pop, "A small-scale DSGE-VAR model for the Romanian economy," Economic Modelling, vol. 67, pp. 1-9, 2017.

[9] E. Bondzie, G. Bartolomeo, and G. Fosu, "Oil price fluctuations and it impact on economic growth: a dsge approach," International Journal of Academic Research in Business and Social Sciences, vol. 4, no. 2, pp. 217-242, 2014.

[10] F. Smets and R. Wouters, "Shocks and frictions in US business cycles: a bayesian DSGE approach," American Economic Review, vol. 97, no. 3, pp. 586-606, 2007.

[11] A. Justiniano, A. Primiceri , and A. Tambalotti, "Investment shocks and business cycles," Journal of Monetary Economics, vol. 57, no. 2, pp. 132-145, 2010.

[12] F. E. Kydland and E. C. Prescott, "Time to build and aggregate fluctuations," Econometrica, vol. 50, no. 6, pp. 1345-1370, 1982.

[13] B. Bao, J. Ma, and M. Goh, "Short- and long-term repeated game behaviours of two parallel supply chains based on government subsidy in the vehicle market," International Journal of Production Research, vol. 58, no. 24, pp. 7507-7530, 2020.

[14] A. Mehrotra, R. Nuutilainen, and J. Pääkkönen, "Changing economic structures and impacts of shocks: evidence from a dynamic stochastic general equilibrium model for China," Pacific Economic Review, vol. 18, no. 1, pp. 92-107, 2013.

[15] J. Miao and T. Peng, Business Cycles and Macroeconomic Policy in China: Evidence from an Estimated DSGE Model, Unpublished manuscript, Boston University, Boston, MA, USA, 2011.

[16] J. Jia, J. Guo, and Z. Wang, "The fiscal-monetary policy mix and exchange rate stability: a dynamic stochastic general equilibrium model with Chinese characteristics," Emerging Markets Finance and Trade, vol. 51, no. 4, pp. 729-746, 2015.

[17] J. Ma, Z. Guo, and Y. Hong, "Demand-supply dynamics in FMCG business: exploration of customers' herd behavior," Nonlinear Dynamics, vol. 98, no. 3, pp. 1669-1681, 2019.

[18] M. Liu and X. Song, "The effects of oil price shocks on China's macro-economy: a DSGE approach," Nankai Economic Studies, vol. 3, pp. 74-96, 2013.

[19] X. Wu and S. Chang, "Economic analysis of the banana price fluctuation," Chinese Journal of Tropical Agriculture, vol. 30, no. 6, pp. 74-77, 2010. 
[20] G. A. Calvo, "Staggered prices in a utility-maximizing framework," Journal of Monetary Economics, vol. 12, no. 3, pp. 383-398, 1983.

[21] J. B. Taylor, "Discretion versus policy rules in practice," Carnegie-Rochester Conference Series on Public Policy, vol. 39, pp. 195-214, 1993.

[22] M. F. Bryan and W. T. Gavin, "A different kind of money illusion: the case of long and variable lags," Journal of Policy Modeling, vol. 16, no. 5, pp. 529-540, 1994.

[23] J. J. Rotemberg, "Sticky prices in the United States," Journal of Political Economy, vol. 90, no. 6, pp. 1187-1211, 1982.

[24] B. Tong, Money, interest rate and asset prices-analyses and forecasts based on a DSGE model, Ph.D. Dissertation, Peking University, Beijing, China, 2010.

[25] Q. Gao and J. Ma, "Chaos and Hopf bifurcation of a finance system," Nonlinear Dynamics, vol. 58, no. 1-2, pp. 209-216, 2009.

[26] J. Ma, Y. Hou, Z. Wang, and W. Yang, "Pricing strategy and coordination of automobile manufacturers based on government intervention and carbon emission reduction," Energy Policy, vol. 148, Article ID 111919, 2021.

[27] J. Ma and H. Ren, "Influence of government regulation on the stability of dual-channel recycling model based on customer expectation," Nonlinear Dynamics, vol. 94, no. 3, pp. 1775-1790, 2018.

[28] Y.-B. Wang and C.-W. Ho, "No money? No problem! The value of sustainability: social capital drives the relationship among customer identification and citizenship behavior in sharing economy," Sustainability, vol. 9, no. 8, p. 1400, 2017.

[29] H. Fu, C. Huang, Z. Teng, and Y. Fang, "Market structure, international competitiveness, and price formation of Hainan's fruit exports," Discrete Dynamics in Nature and Society, vol. 2021, Article ID 6664780, 13 pages, 2021.

[30] B.-H. Lin, S. Yen, C. Huang, and T. Smith, "U.S. Demand for organic and conventional fresh fruits: the roles of income and price," Sustainability, vol. 1, no. 3, pp. 464-478, 2009.

[31] J. Ma, Y. Hou, W. Yang, and Y. Tian, "A time-based pricing game in a competitive vehicle market regarding the intervention of carbon emission reduction," Energy Policy, vol. 142, Article ID 111440, 2020.

[32] H. Huang, B. Shen, and T. Wang, "The effects of bank ownership on lending behaviour for different types of loans throughout the business cycle," International Finance, vol. 22, no. 2, pp. 201-220, 2019.

[33] J. Ma and L. Xie, "The comparison and complex analysis on dual-channel supply chain under different channel power structures and uncertain demand," Nonlinear Dynamics, vol. 83, no. 3, pp. 1379-1393, 2016.

[34] X. Su, H. Liu, and S. Hou, "The trilateral evolutionary game of agri-food quality in farmer-supermarket direct purchase: a simulation approach," Complexity, vol. 2018, Article ID 5185497, 12 pages, 2018. 